\title{
Research on the Relationship between Geographical Factors, Sports and Culture
}

\author{
Minyong Song, Yang Zhang \\ Xi'an University of Science and Technology, Xi'an, China \\ Email: zhyang1982@126.com
}

How to cite this paper: Song, M. Y., \& Zhang, Y. (2018). Research on the Relationship between Geographical Factors, Sports and Culture. Advances in Physical Education, 8, 66-70.

https://doi.org/10.4236/ape.2018.81008

Received: November 8, 2017

Accepted: February 10, 2018

Published: February 13, 2018

Copyright $\odot 2018$ by authors and Scientific Research Publishing Inc. This work is licensed under the Creative Commons Attribution International License (CC BY 4.0).

http://creativecommons.org/licenses/by/4.0/

(c) (i) Open Access

\begin{abstract}
In order to find out the relationship between geographical factors and sports and their culture, and to achieve the harmonious development between them, the methods of literature and logical analysis were used to study the influence of climate factors, terrain factors and geographical factors on sports and its culture. Climate changes will affect the sports conditions, but also interfere with the athletes' body mechanism and emotion, thereby affecting athletic ability. Topography has a great influence on the emergence and development of sports. The geographical environment is closely related to sports and sports culture. The difference of human culture is related to the local geographical environment and national characteristics. Every ethnic culture is derived and developed under the influence of a specific natural geographical environment. At the same time, in the development and promotion of sports and sports culture, the geographical environment will produce positive and negative changes.
\end{abstract}

\section{Keywords}

Geographical Factors, Sports, Culture, Relationship

\section{Introduction}

Man-earth relationship (Zhou \& Chen, 2007) is a natural relationship that has existed since mankind was born and multiplied, because human survival, reproduction, development cannot be separated from the geographical environment. Land is the soil that breeds human beings. Especially in primitive society and slave society with low productivity, humans have a strong dependence on the land (Zhou \& Chen, 2007). With the continuous development of science and technology, human has larger ability to change the nature and depends less on the geographical environment. But it is undeniable that the geographical envi- 
ronment has always been the material basis for people's production and life. With an exception on physical activities, geographical environment, climatic conditions, political conditions, economical conditions and cultural conditions in a certain area have a profound impact on sports. Therefore, studying the relationship between geographical environment and sports and its natural culture can provide valuable reference for the healthy and long-term development of sports in China.

\section{Influence of Geographical Factors on Sports Events}

\subsection{Climatic Factors}

Climate condition is one of the most important factors that affect the regional development of sports. Climate conditions affect not only the feasibility of sports, but also the athletes' good mood and physiological function. People have different lifestyles and physical exercises under different climates, such as Norwegians living in the Arctic Circle. Because the area belongs to the subfrigid coniferous forest climate zone and it is close to Arctic Ocean and Norwegian Sea, People in the region mainly play ice sports owning to the cold weather. Countries such as Ecuador, which live near the equator, belong to the tropics. Sprint, long jump, surfing and other sports which are in accordance with the local climatic conditions are prevalent owning to the hot weather and long lighting time.

\subsection{Topographic Factors}

Many sports events are closely related to the local topography. For example, people in the area of steep cliffs are more likely to do rock climbing, mountain climbing and abseiling; people living in the area with vast coastline are prone to swimming, surfing and other sports; people in plain terrain and plateau areas tend to run races, horse riding and other sports. Different geographical environment gave birth to different sports. Topography, mountains, rivers and different geographical environment form different sports events. For instance, people in Switzerland, Austria and other countries near the Alps advocate skating; Australia, the United States, New Zealand and other countries have rich coastal resources and people there advocate surfing, windsurfing; Africa has the world's largest plain-the Amazon plain, so Africans are good at long-distance running; terrain in our country is very complex, so there are many kinds of sports. Chinese minority Qiang live in lofty mountains and steep hills with lots of rivers, therefore archery, javelin and other technological sports are prevalent there.

\section{Influence of Geographical Factors on Sports Culture}

\subsection{Regionality of Sports Culture}

The regionality of sports culture refers (Lin, 2016) to the different characteristics 
of sports culture due to the limitation of geographical environment. That is to say, different geographical conditions have different sports culture. Facing the Pacific Ocean in the East, China has criss-cross mountains, hills, plateaus, plains, basins, rivers and lakes. There is a great difference in humidity and temperature all over China. Natural belt from southeast to northwest is forest, grassland and desert in turn. The complex terrain, soil, climate, hydrology and other natural conditions form different regional characteristics. There are large and small Xingan ridge and outer Xingan ridge in Northeast China. The North Mongolia plateau and extremely cold Siberia exist to the north. The Qinghai Tibet Plateau, known as the roof of the world, and the Hengduan Mountains are stand in the southwest of China. East of China is the largest ocean in the world - the Pacific Ocean. The geographical environment of the sea and the three sides of the land make the ancient Chinese people separated from the outside world, formed a relatively isolated state. The relatively closed geographical environment breeds a relatively conservative traditional culture. European culture originated from the Mediterranean coast which is surrounded by Europe, Asia and Africa, especially in the eastern Mediterranean Aegean Sea islands and Greek peninsula. So ancient Greek culture is the birthplace of European Civilization. Greece is mainly composed by islands. The largest peninsula is Peloponnese and the largest island is Grete. Greece has many mountains, but few plains, short rivers, resulting poor farm land for agriculture. The lack of resources, the adventure of the sea and the frequent military conflicts in the city-state compel people to learn to fight against nature and enemies. Undoubtedly, these are the most important reasons why ancient Greek sports are full of competitive spirit. "Contention" in sports refers to the idea that western sports emphasize individuals and emphasize man's transcendence of nature. Their sports competition advocates "higher, faster, stronger".

\subsection{Nationality of Sports Culture}

The nationality of sports culture refers to (Lin, 2016) the national sports culture which is different from other ethnic groups due to the differences of living space, living environment, production, life style and cultural influence in history. Any nation's sports culture is happening and developing in a relatively fixed geographical space, and gradually become the common cultural phenomenon of the whole nation. Therefore, any sports culture belongs to a nation, and the super national sports culture can not exist. However, when a nation's sports culture grows to a certain extent, it will inevitably break through the old drive and spread to the outside to contact with the sports culture from other ethnic groups, or to be passively influenced by the outside. For example, the oriental sports culture represented by Chinese sports, because of the geographical environment and multi-ethnic characteristics, make Chinese have the idea of "harmony between man and nature", advocating nature and forming introverted character. They are good at non physical events, such as gymnastics, diving, table tennis 
and so on. Taking the western sports culture represented by Europe and the United States as an example, the complexity of race, outgoing personality and the pursuit of personality make them good at intense physical contact projects, such as boxing, rugby, etc.

\section{The Counteractive of Sports to Geographical Environment}

\subsection{Positive Influence}

Today, with the rapid development of science and technology, people can make full use of wisdom to reduce the impact of geographical factors on sport events and sport culture. Through transforming the natural environment and creating some sports equipment as well as venues to meet people's desire for physical exercise, such as treadmills, indoor basketball halls, indoor swimming pools and artificial skiing grounds.

\subsection{Negative Influence}

Sports have obtained unprecedented development because of social demand and progress in science and technology. The scope of people's sports activities has been greatly expanded. The surrounding environment is becoming worse in excessive human intervention. Especially when people's productivity level is not perfect, people are not aware of the adverse effects of their sports activities on the natural environment. In the process of actual sports development (Zhang, Qan, \& Chang, 2013), the pollution of the natural environment including air pollution, water pollution, noise pollution and the construction of sports facilities and places will destroy the topography and landforms and reduce the biodiversity. The effect of these pollutions on the natural environment directly restricts the sustainable development of sports.

\section{Conclusion}

1) Sports are always carried out in a specific natural environment and social environment. The geographical environment influences the emergence and development of sports events in different ways, Climate changes will affect the conditions of sports, but also interfere with the athletes' body mechanism and emotion, thereby affecting athletic ability. Topography has a great influence on the emergence and development of sports.

2) The geographical environment is closely related to sports and sports culture. The difference of human culture is related to the local geographical environment and national characteristics. Every ethnic culture is derived and developed under the influence of a specific natural geographical environment.

3) In the development and promotion of sports and sports culture, the geographical environment will produce positive and negative changes.

\section{References}

Lin, F. L. (2016). Sports Geography (pp. 42-50). Hangzhou: Zhejiang University Press. 
Zhang, Y. D., Qan, Y., \& Chang, Q. (2013). On Sports and Natural Environment. Journal of Huaihai Insititute of Technology (Humanities \& Social Sciences Edition), No. 10, 128-130.

Zhou, Q., \& Chen, L. (2007). Research on the Relationship between the Development of Sports and Geographical Environment. Science and Technology Consulting Herald, No. 15, 160. 